\title{
A origem e o destino: superação da natureza entre o belo e a liberdade no pensamento estético de Friedrich Schiller
}

\section{Gabriel Lago de Sousa Barroso, UFMG}

Resumo: Na estética de Friedrich Schiller, a arte assume uma função política fundamental, na medida em que, na sua interpretação do projeto da modernidade, ela é condição de possibilidade da ação política autêntica. O presente trabalho busca compreender como a atividade do artista representa uma superação das aporias apontadas por Schiller em sua crítica cultural da modernidade, principalmente a partir da tese de relação originária entre a produção artística, a natureza e o ideal.

Palavras-chave: Modernidade; educação estética; liberdade estética.

Mas cabe a nós, poetas!

Permanecer com a cabeça descoberta Baixo as tormentas de Deus,

Empunhar com nossas próprias mãos

$O$ raio mesmo do pai e

Entregar ao povo, envolto

No canto, o dom celeste.

Friedrich Hölderlin, Como em dia de festa... ${ }^{1}$

Qual é o dom celeste que cabe ao poeta entregar ao povo, o dom que Hölderlin anuncia em sua poesia? O poeta certamente guarda algo aos seus contemporâneos, algo que não lhes é completamente estranho, mas que, talvez, encontre-se perdido. Ao escrever estes versos em 1800, Hölderlin pensa a relação entre poeta e povo, ou a posição mediadora que a poesia assume a respeito da comunidade de homens. Pode-se especular se o fazia sob a influência do protetor que tanto admirava, Friedrich Schiller. Ambos compartilhavam essa mesma preocupação, sob o reflexo da história de sua época. Também este problema anima o presente estudo, na medida em que se busca compreender a função do conceito de natureza em alguns dos trabalhos teóricos de Schiller, e em que medida este conceito se articula com a dimensão política assumida em suas reflexões estéticas. O que se encontra no centro deste questionamento é a relação entre ética e estética, a qual encontra na obra de Schiller o locus ideal para uma investigação preliminar. Muito pode ser conquistado pela análise deste momento fundador da modernidade. ${ }^{2}$

Schiller é um homem marcado pelos ideais revolucionários, e um arguto analista de seus desenlaces na França. Em uma carta de 1793 dirigida ao duque de Augustenburg, pode ser vislumbrada a intensidade com que o poeta depositava suas esperanças na abertura revolucionária: 
Fosse verdadeiro o fato - tivesse ocorrido realmente o caso extraordinário de que a legislação política fora confiada à razão, de que o homem fora respeitado e tratado como um fim em si mesmo, de que a lei fora elevada ao trono e a verdadeira liberdade tornada em fundamento do edifício do Estado, então queria despedir-me eternamente das musas e dedicar toda minha atividade à mais magnífica de todas as obras de arte, à monarquia da razão. Mas este fato é justamente o que ouso pôr em dúvida. Sim, estou tão longe de crer no início de uma regeneração no âmbito político (Regeneration im Politischen), que os acontecimentos da época antes me tiram por séculos todas as esperanças disso. ${ }^{3}$

Ao lado de um comprometimento tão alto com o ideal, fica também claro seu desencanto com a realidade, o juízo cético a respeito do futuro da Revolução, a descrença em uma "regeneração da política". Degeneração e regeneração são termos nada estranhos às reflexões de Schiller. Seus lamentos se dirigem aos eventos de 1792 e 1793 - a degeneração da Revolução no Terror de Robespierre. A radicalização da Revolução em um estágio de terror (em uma "liberdade do vazio" como Hegel descreveu em sua Filosofia do Direito) é o ponto de inflexão na vida política da Europa, a que Schiller não permanece insensível. Sua carta de 1793 demonstra a que ponto a fé nos ideais revolucionários pôde abrir horizontes, e o abismo em que estes foram jogados com a propagação da violência. Os motivos da catástrofe são avaliados por ele na mesma carta:

A tentativa do povo francês de estabelecer-se nos seus sagrados direitos humanos e conquistar uma liberdade política trouxe a lume apenas a incapacidade e a indignidade do mesmo, e lançou de volta à barbárie e à servidão não apenas este povo infeliz, mas, com ele, também uma considerável parte da Europa, e um século inteiro. O momento era o mais favorável, mas encontrou uma geração corrompida que não mais lhe era merecedora e não soube nem dignificá-lo nem utilizá-lo. ${ }^{4}$

Schiller vangloria a mais magnífica das obras de arte, que é a monarquia da razão, e daria adeus às musas, fosse o governo da razão um fato. Mas o que se observa é o oposto: nas mãos de um povo sem capacidade, sem dignidade, o que se vê é o retorno à barbárie e à servidão, o retrocesso em detrimento do progresso. "A uma grande época deu a luz o século,/ mas o grande momento encontrou uma pequena geração". ${ }^{5} \mathrm{O}$ diagnóstico do fracasso se dirige à incapacidade dos homens em conduzir a Revolução. É a estes, a esta "pequena geração", que cabe a responsabilidade da violência. Uma humanidade degenerada jamais poderia regenerar a política, e a grande obra do ideal ficaria por ser construída, interrompida pela catástrofe da história.

É neste contexto de desilusão política que Schiller constrói sua reflexão estética. Se o poeta não pôde abandonar as musas e dedicar suas forças à obra concreta da razão, sua estética é marcada pela preocupação com seu tempo ("não quero viver noutro século, nem quero ter trabalhado para outro"6), distante de uma contemplação desinteressada. Em Schiller, o pensamento do belo tem suas bases conceituais na filosofia transcendental de Kant, mas é a todo o momento conduzido à dimensão histórico-filosófica, em um processo constante de mediação que o impede de se perder na pura abstração do pensamento. Nisso segue o preceito hermenêutico de realizar, previamente à atividade interpretativa, a apropriação da própria situação de compreensão. $\mathrm{O}$ resultado imediato da presença de uma leitura histórica na estética é que seu interesse passa a transcender a análise do belo e do sublime para garantir um papel ímpar às artes em geral, pois o poeta 
se pergunta pela função da arte e do belo no processo de civilização. Schiller, o historiador, notou a decadência da cultura e dos homens: Schiller, o poeta, pergunta-se se a arte tem a capacidade de inverter esse quadro. Central para o seu argumento é a tese de que a falência política de seu tempo pode ser revertida pela experiência estética - "para resolver na experiência o problema político é necessário caminhar através do estético, pois é pela beleza que se vai à liberdade". ${ }^{7}$ A beleza abre as portas para a mediação entre natureza e liberdade, de modo a mitigar a oposição encontrada no pensamento kantiano, pois a beleza é a objetificação (Vergegenständlichung) da liberdade no reino do fenômeno.

Neste caminho, salta ao primeiro plano a relação entre ética e estética. Na medida em que a natureza é o fundamento referencial da estética, também ela determina de alguma forma a via que leva à liberdade. São os limites dessa influência que importa aqui definir com maior precisão ${ }^{8}$. Antes, porém, é preciso compreender o pressuposto da tese de Schiller, que é sua crítica cultural.

\section{Crítica cultural}

Se a reflexão sobre a natureza e antropologia em A educação estética do homem numa série de cartas busca o ponto de vista da filosofia transcendental, seus fundamentos históricos não se disfarçam em Schiller. A crítica ao povo francês feita nas cartas ao duque de Augustenburg, as quais serviram de base à obra sobre a educação estética, não remete a uma contingência histórica, mas é reflexo de uma condição moderna, cuja origem histórica pode ser rastreada. Schiller insere-se aqui, na esteira de Rousseau, em uma então recente tradição de crítica cultural, que se dirige fundamentalmente à cultura da Aufklärung. Trata-se de distinguir em instituições e na moral os motivos que levam a uma "humanidade decaída", empreender sua crítica e desbravar possíveis caminhos para sua reforma. ${ }^{9}$ Este mapeamento crítico da dimensão cultural é fornecido em A educação estética do homem, tanto a respeito da esfera exterior (o Estado e a sociedade) quanto da esfera interior (a natureza humana).

A decadência humana se apresenta em dois extremos: a selvageria e a lassidão. A selvageria é típica das classes mais baixas e numerosas, e é descrita como o comportamento segundo "impulsos grosseiros e sem lei". Schiller sublinha a dissolução dos vínculos da sociedade civil a que levam tais impulsos, e como sua finalidade nada mais é que a satisfação animal. "A sociedade desregrada recai no reino elementar em vez de ascender à vida orgânica". ${ }^{10}$ A selvageria é uma adesão à natureza bruta, muito distante da natureza descrita em Poesia ingênua e sentimental. Prepondera a animalidade, não a harmonia, o elementar, e não o orgânico.

A lassidão é o oposto da selvageria, pois provém das classes civilizadas, marcadas pela languidez e a depravação do caráter. Trata-se aqui de costumes formados, e não do estado bruto da animalidade, mas prevalece a torpeza moral das classes afundadas no próprio egoísmo, na ausência de virtude que marca o individualismo míope. Estes, para Schiller, por terem sido educados, são tanto mais dignos de reprovação que os selvagens. A crítica à cultura da Aufklärung já se delineia: “A ilustração do entendimento (Aufklärung des Verstandes), da qual se gabam não sem razão os estamentos refinados, mostra em geral uma influência tão pouco enobrecedora sobre as intenções que até, pelo contrário, solidifica a corrupção por meio de máximas". ${ }^{11} \mathrm{Na}$ quarta carta, esses dois tipos são descritos como o selvagem e o bárbaro. É notável que, na tipologia schilleriana, o homem da ilustração seja o bárbaro, cujos "princípios destroem seus sentimentos". ${ }^{12}$ 
A comparação com a civilização grega revela que a nota essencial do homem moderno é a sua fragmentação. No indivíduo moderno, as faculdades da mente manifestam-se cindidas na experiência, e não só alguns sujeitos, mas classes inteiras desenvolvem-se aquém de suas potencialidades. O subdesenvolvimento das potencialidades não é responsabilidade única de indivíduos marcados por lassidão e selvageria. Não se fala em culpa individual, mas de um processo impulsionado pela cultura, "que abriu essa ferida na humanidade moderna”. A crítica cultural de Schiller não prescinde, pois, de avançar à esfera objetiva, na medida em que é a constituição do Estado, em sua relação com a sociedade, que determinou a limitação individual que se observa entre os modernos. Por um lado, a fragmentação das ciências foi resultado da "experiência ampliada" e do "pensamento mais preciso"; por outro, a complexificação da sociedade levou os Estados a uma delimitação dos estamentos e negócios, cuja consequência primeira foi a divisão social do trabalho, rompendo-se assim "a unidade interior da natureza humana". Forjamse as mais diversas dicotomias na natureza humana - sentidos e razão, arte e erudição, entendimento intuitivo e especulativo, imaginação luxuriosa e espírito abstrato. Esse processo, embora visto como deletério, é considerado por Schiller inexorável. Surge do aprofundamento científico e do desenvolvimento da sociedade, e é agravado pela atividade do Estado. O homem que se forma nesse contexto é o componente da geração corrompida, que, em sua fragmentação, jamais suportaria o projeto radical de uma revolução da sociedade. ${ }^{13}$ "Eternamente acorrentado a um pequeno fragmento do todo, o homem só pode formar-se enquanto fragmento". ${ }^{14}$ A importância e a necessidade de uma educação estética surgem na modernidade, já que de homens fragmentados e decaídos não se abre uma janela ampla o suficiente para a transformação da sociedade. O que Schiller busca, portanto, para a consecução dos antigos ideais é uma visão clara da natureza deste homem, de modo a agir como o médico que diagnostica a fraqueza do corpo para, então, reconstituir sua força original.

\section{A natureza como marca da origem}

Em Schiller, a natureza responde ao chamado de uma humanidade decaída. Como uma marca do vazio, a totalidade originária do homem, perdida, ainda se presentifica frente à visão de seu passado. Sua crítica cultural deságua em uma rejeição radical ao positivo (positiv). Esse termo, utilizado na nona carta, designa tudo aquilo que é factual, histórico, válido socialmente, e por isso também sujeito à corrupção. ${ }^{15} \mathrm{~A}$ pergunta que surge é, pois, como superar o império da positividade, como escapar ao ciclo vicioso entre corrupção da política e decadência do indivíduo. Por este motivo, o Estado, tendo sido, em sua forma presente, a origem do mal, jamais poderia habilitar-se como uma saída ao problema. ${ }^{16}$ A possibilidade de uma educação estética encontra-se vinculada à ideia de que a arte não se degenera imersa na positividade da sociedade, de que portanto sua origem não está submetida à história, e assim transcende a decadência do tempo. "Arte e ciência são livres de tudo o que é positivo, e que foi introduzido pelas convenções dos homens; ambas gozam de uma absoluta imunidade em face do arbítrio humano". ${ }^{17} \mathrm{~A}$ imunidade da arte deriva de sua fundação, não em formas mutáveis de um gosto de época contingente e degenerado, mas "no necessário e no eterno da natureza humana, nas leis originárias do espírito". ${ }^{18}$ Por isso, a arte pode, mesmo em um século bárbaro, transformar-se em algo "puro como um celestial", contanto que ela permaneça sob o signo de sua "alta origem". A autonomia da esfera estética certamente é um pressuposto da potencialidade reformadora da arte. 
A imunidade à positividade, bem como a capacidade crítica e transformadora da arte, vincula-se portanto à sua ligação com "as leis originárias do espírito" e sua "alta origem". Qual o significado desse caráter originário da arte e por que essa conexão permite-lhe, no projeto de Schiller, assumir prioridade em relação à obra política?

O ensaio Sobre poesia ingênua e sentimental é decisivo para o aprofundamento da questão. $\mathrm{O}$ escrito é marcado por um forte caráter psicológico, decorrente dos embates com Goethe, que em muito o inspiraram. ${ }^{19}$ Interessa a Schiller compreender, em um primeiro momento, o interesse do homem pela natureza, por aqueles objetos que nele despertam um tipo de amor e tocante respeito, como flores e animais, o campo e seus habitantes e os produtos da antiguidade remota. Esses objetos, além de naturais, devem ser ingênuos, ou seja, é necessário que neles "a natureza esteja em contraste com a arte e a envergonhe". ${ }^{20}$ A relação dialética entre natureza e cultura surge já ao início do ensaio, e Schiller logo em seguida enuncia a essência da relação entre o homem civilizado e a natureza corporificada nestes objetos:

São (sind) o que nós fomos (waren); são o que devemos vir a ser de novo (wieder werden sollen). Fomos natureza como eles, e nossa cultura deve nos reconduzir à natureza pelo caminho da razão e da liberdade. São, portanto, expressão de nossa infância perdida, que para sempre permanece como aquilo que nos é mais precioso; por isso, enchem-nos de uma certa melancolia. Ao mesmo tempo, são expressões de nossa suprema completude no Ideal, transportando-nos, por isso, a uma sublime comoção. ${ }^{21}$

O contato com os objetos naturais despertam no homem civilizado a melancolia, por lhe trazer o sentimento daquilo que ele foi um dia, daquilo que ele não é mais. Esse passado distante que ressurge na melancolia é o mesmo que, na descrição da Grécia clássica na sexta carta de A educação estética do homem ("naqueles dias do belo despertar das forças espirituais, os sentidos e o espírito não tinham ainda domínios rigorosamente separados; a discórdia não havia incitado ainda a divisão belicosa e a demarcação de fronteiras" ${ }^{22}$ ), revelava o caráter fragmentário do homem moderno. Afirma-se aqui que a cultura deve nos reconduzir à natureza, reconstruir, portanto, a unidade do homem cindido.

No conceito de natureza de Schiller está contido o traço das leis imutáveis, as mesmas leis que nas cartas ao conde de Augustenburg definiam a capacidade da poesia de extrapolar seu tempo: "Natureza, considerada deste modo, não é para nós senão o ser espontâneo, a subsistência das coisas por si mesmas, a existência segundo leis próprias e imutáveis". ${ }^{23} \mathrm{O}$ que constitui a natureza nessa passagem, em contraposição à humanidade civilizada, é que a natureza é regida por leis, marcada portanto pela necessidade, ao passo em que o homem é mutável, arbitrário, e ultrapassa a natureza para cair na contingência de suas próprias ações. Entretanto, é preciso distinguir o modo pelo qual a natureza mostra sua superioridade perante a arte. Schiller diferencia a grandeza dinâmica da grandeza moral. Pela primeira, a natureza é caracterizada por sua violência cega, pela carência. Na segunda, a marca da natureza é sua forma, a necessidade interna que revela como lei da harmonia (Gesetze der Übereinstimmung). ${ }^{24}$ Apenas a natureza que revela a grandeza moral pode triunfar sobre arte (considerada enquanto artifício, técnica, que caracteriza a modernidade): a natureza enquanto harmonia, e não enquanto carência. Em sua crítica cultural nas Cartas, o homem selvagem é criticado por sua proximidade a esta violência cega, pois o que resulta de sua natureza é carência e desejo, que levam à 
violência, e não o caráter harmônico definidor da natureza que serve de modelo nos ensaios.

O processo teorizado por Schiller (como ficará claro na crítica a Rousseau) não vai, entretanto, por uma simples volta ao estado de natureza: a arte deve reconstruir a unidade levando o homem ao ideal (Ideal) que, embora se referencie à unidade originária, vai além desta. Trata-se de um terceiro momento, estético, em que a unidade da natureza é reestabelecida a partir de uma dialética com a cultura civilizada: "somos livres e eles, necessários; mudamos, eles permanecem iguais. Mas apenas quando se ligam uns aos outros - quando a vontade segue livremente a lei da necessidade e a razão afirma sua regra em toda alternância da fantasia -, é que surge o divino ou o Ideal". ${ }^{25}$ A estrutura triádica, exposta por Schiller de modo histórico-filosófico, parte (i) da unidade da natureza, o impulso natural que contém em si uma fonte moral; a que se segue (ii) a cisão pela arte (como técnica), o processo civilizatório que separa entendimento e sentimento na natureza humana; e aponta para (iii) a reconstituição, como tarefa e finalidade do futuro, na forma do ideal. "Este caminho que os poetas modernos seguem é, de resto, o mesmo que o homem em geral tem de trilhar, tanto individualmente quanto no todo. A natureza o faz uno consigo; a arte o cinde e desune; pelo Ideal, ele retorna à unidade". 26

O agente da recondução à unidade, nos dois ensaios, é o poeta, considerado enquanto gênio, pela identidade do processo tanto em relação ao indivíduo quanto à sociedade, bem como por sua capacidade de escapar ao império da positividade. A relação entre o poeta e a natureza é constitutiva desta capacidade. O diagnóstico de Schiller sublinha o fato de que na sociedade moderna não há mais espaço para a natureza. Mas nas artes essa natureza originária é conservada. O poeta é, segundo o seu conceito, o guardião da natureza. ${ }^{27} \mathrm{Na}$ condição de sujeito, ele conserva em si tanto a presença do natural quanto da ingenuidade, assim como os objetos designados no início do ensaio. Sua ingenuidade é ligada à sua infantilidade (Kindlichkeit), capaz de demonstrar o direito da natureza e o erro do artifício. O poeta-gênio desconhece regras, fraquezas e a perversidade, é guiado apenas pela natureza ou pelo instinto, seus "anjos protetores", e triunfa sobre seu tempo auxiliado por seu interior. "Apenas ao gênio é dado estar sempre em casa fora do que é conhecido e ampliar a natureza sem ir além dela". ${ }^{28}$ Isso justifica que, mesmo em uma época como a moderna, com sua "contrariedade à natureza", o gênio possa se guiar por essa natureza, independente das regras que regem a sociedade. ${ }^{29}$

Não se trata, portanto, de ações arbitrárias em seu caso, mas verdadeiramente de inspirações e sentimentos, que por estarem intimamente conectados à natureza harmônica, escapam à positividade, e podem recuperar aos contemporâneos a harmonia perdida. O gênio não é arbitrário, mas sim marcado pelo "que há de necessário e eterno na natureza humana", pelas "leis originárias do espírito". É nesse sentido que Schiller os considera guardiões da natureza:

Onde já não o possam ser completamente, onde já tenham experimentado em si mesmos a influência de formas arbitrárias e artificiais ou tenham tido de combatê-la, surgirão como testemunhas ou vingadores da natureza. Serão natureza ou buscarão a natureza perdida. ${ }^{30}$

A relação do poeta com a sociedade, na descrição de Schiller, não é conflituosa, mas tampouco harmoniosa. Em todo caso, é marcada pela tensão identidade-diferença. Pois o gênio poético sublinha a ausência da natureza na sociedade na relação de contraste com suas características próprias, como no caso de sua linguagem, cujo traço é o caráter 
genuíno, a simplicidade e a rigorosa verdade da expressão, uma linguagem ainda não contaminada pela distância entre cálculo e discurso que define os circunlóquios da civilização. O poeta dá a cada coisa o seu nome certo e usa do caminho mais curto para isso. ${ }^{31}$ Por outro lado, na medida em que sua presença aponta para um vazio, que é sentido enquanto ausência, sua relação possui uma mínima identidade, a da origem comum.

\section{Liberdade estética e obra política}

Se a poesia se constitui como uma esfera autônoma, que escapa à positividade, e encontra suas raízes em uma natureza harmoniosa, qual sua relação com a obra política e com a análise da modernidade como momento de cisão?

$\mathrm{O}$ projeto de reconstituição da unidade do homem é aqui o motivo central para Schiller. Reconstituir, no entanto, não tem em suas reflexões o sentido de um retour à la nature. Não deixa dúvida disso a crítica feita a Rousseau em Poesia ingênua $e$ sentimental. Sua análise de La Nouvelle Heloüse constata um poeta de sensibilidade aguçada e pensamento profundo, mas que falha em instaurar entre as duas dimensões o jogo poético. Com isso, o ideal que apresenta à humanidade privilegia os limites do homem, mas considera pouco suas potencialidades. O resultado final disso é a decisão de se livrar do conflito, e não de superá-lo: Rousseau prefere conduzir a humanidade à "uniformidade sem espírito do primeiro estado", e rebaixar a meta do ideal. ${ }^{32}$

É importante observar, nesse ponto, a diferença entre natureza e ideal. ${ }^{33}$ Schiller julga impossível o retorno ao estado de natureza. A crítica cultural já havia demonstrado que a formação de cisões era inexorável à história da civilização. No estado cultural, a harmonia que na natureza pura existia entre sentir e pensar já não existe realmente. Mas isso não significa que ela não exista idealmente. A harmonia pode existir como unidade moral, isto é, não mais como "um fato da vida", mas como "um pensamento que deve ser realizado". ${ }^{34}$ Natureza, nesse sentido, diz respeito a um estado de harmonia original, e, enquanto ideal, significa a existência da ideia de harmonia no pensamento.

O conceito de poesia em Schiller permite esclarecer um pouco mais seu projeto poético-político, em ligação aos estados natural e cultural. Poesia, ele enuncia, é "dar à humanidade a sua expressão mais completa possível". ${ }^{35}$ Esse conceito se manifesta de modos diferentes na natureza e na cultura. Em uma sociedade em relação ainda harmônica com a natureza - como seria a Grécia clássica - o poeta, para dar expressão à humanidade, deve imitar a realidade, ao passo em que no estado de cisão com a natureza - o caso da modernidade - o que constitui o poeta é "a elevação da realidade ao Ideal ou, o que dá no mesmo, é a exposição do Ideal". ${ }^{36}$

É central para a relação entre estética e ética o modo como, por meio do conceito de ideal, a poesia se relaciona com a sociedade. Isso é retomado por Schiller com um explícito caráter político em A educação estética do homem. Por meio do conceito de ideal, abre-se espaço ao artista pedagogo e político que, comparado ao artista mecânico e ao artista do belo, tem o homem, ao mesmo tempo, como seu material e tarefa. ${ }^{37}$

A conhecida teoria antropológica dos impulsos, desenvolvida nas Cartas, é a base sobre a qual pode ser formulada uma educação estética de influência política. Segundo Schiller, a natureza humana é composta por dois impulsos. Por um lado, um impulso sensível, que liga o homem à vida, à sensibilidade e realidade, que se enraíza no âmbito de sua existência finita; por outro, um impulso formal, que se liga à lei e à natureza racional do homem, que domina o âmbito da eternidade. Enquanto o sentimento se liga ao primeiro impulso, o pensamento se liga ao segundo. ${ }^{38}$ Estes dois impulsos, embora se 
fundem em domínios diferentes, tendem a extrapolar suas jurisdições e subjugar um ao outro. A crítica ao homem formado pela Aufklärung deriva exatamente do diagnóstico de sua particularização, o homem cujos "princípios destroem seus sentimentos", uma vez que um dos impulsos (o formal) tem toda a prioridade e aniquila o outro.

A tarefa da cultura é, pois, harmonizar esses dois impulsos, assegurando a salvaguarda de ambos. Nas palavras Schiller, sua incumbência tem dois lados: "em primeiro lugar, resguardar a sensibilidade das intervenções da liberdade; em segundo lugar, defender a personalidade contra o poder da sensibilidade. A primeira ela realiza pelo cultivo da faculdade sensível; a outra, pelo cultivo da faculdade racional". ${ }^{39}$

Ainda que as Cartas deixem claro que esses dois impulsos correspondem à totalidade da natureza humana ${ }^{40}$, emerge de sua determinação recíproca um terceiro impulso, que é denominado lúdico. O impulso lúdico exprime a totalidade do homem, razão pela qual Schiller afirma que o homem somente é homem pleno enquanto joga. ${ }^{41}$ Ao combinar sensibilidade e razão, finito e infinito, o impulso lúdico se apresenta como o elemento capaz de restituir ao homem sua humanidade. Em Schiller, essa reconciliação dos contrários no lúdico é que caracteriza a beleza ${ }^{42}$, do mesmo modo como seu conceito de poesia correspondia à expressão mais completa possível da humanidade. O homem verdadeiramente cultivado corresponde a essa recomposição dos opostos. ${ }^{43}$

É da restituição dessa harmonia - da qual o impulso lúdico é o corolário - que surge a ideia de uma liberdade garantida pela cultura estética, conceito enunciado por Schiller na vigésima primeira carta e que estabelece a fronteira entre estética e obra política. A ausência de liberdade do homem provém precisamente de sua submissão à coerção ${ }^{44}$ por um lado, a coerção unilateral da sensação e, por outro, a da legislação exclusiva da razão no pensamento. Somente a educação estética pode recuperar essa liberdade, pois na medida em que reconcilia o homem, garante a ela a plena abertura a suas potencialidades.

$\mathrm{O}$ processo de restituição da liberdade pela via estética encontra-se no ponto de chegada da cultura, como uma infinitude plena. Enquanto no estado natural o homem é caracterizado por uma infinitude vazia, a ausência de qualquer determinação de seu ser por falta, na infinitude plena se dá o oposto: o homem, por combinar em si todas suas determinações na totalidade de sua humanidade, encontra-se sem quaisquer limitações de seu ser e é, portanto, livre. Exatamente por sua liberdade consistir na ausência de limites, Schiller afirma que no estado estético (ästhetischer Zustand) o homem é zero, isto é, é plenamente potente em virtude da ausência de determinações particulares. ${ }^{45} \mathrm{~A}$ arte, portanto, "não realiza, isoladamente, fins intelectuais ou morais, não encontra uma verdade sequer, não auxilia nem mesmo o cumprimento de um dever, e é, numa palavra, tão incapaz de fundar o caráter quanto de iluminar a mente". ${ }^{46} \mathrm{O}$ que a arte garante ao homem é a plena potencialidade de "pela natureza fazer de si mesmo o que quiser", isto é, "a liberdade de ser o que deve ser".

Fica claro que esta não é a liberdade política pela qual o século de Schiller tanto lutou. A liberdade estética, enquanto restitui ao homem sua humanidade é, na verdade, a condição de possibilidade dessa liberdade. ${ }^{47}$ Dessa preponderância deriva o caráter essencial de uma educação estética para a vida política da modernidade - a Bildung necessária à consecução do projeto moderno. Em virtude disso, Schiller afasta toda a possibilidade de uma arte didática ou corregedora da moral ${ }^{48}$, em que o artista se coloca como um sábio detentor do conhecimento a ser transmitido aos seus contemporâneos. $\mathrm{O}$ verdadeiro artista, em sua condição de criador, não se foca na matéria, mas sim na forma, pois somente a forma atinge o todo do homem. ${ }^{49}$ No caso do artista pedagogo e político, sua obra de arte é o próprio homem, isto é, a liberdade estética que desperta no homem, garantindo-lhe a posse de suas próprias potencialidades. De modo coerente, o Estado 
estético "utópico" "50, apresentado na última carta, descreve as relações intersubjetivas como forma, em que um homem está diante do outro como objeto do livre jogo, livre de coerções, e por isso sua lei fundamental é "dar liberdade através da liberdade". ${ }^{51}$ Dessa maneira, parece correta a análise de Habermas de não ser a intenção de Schiller a estetização das relações de vida, mas, antes, a constituição da arte como um medium pelo qual a humanidade possa se formar para a liberdade política. ${ }^{52}$

Assim, a liberdade estética tem em comum com a natureza a restauração da harmonia original no homem. Esse é o dom celeste que, no canto, a arte pode entregar ao povo, como um dom político. Embora isso signifique uma superação da natureza - para sempre perdida -, significa, também, sua recuperação como uma segunda criação:

Não é, portanto, mera licença poética, mas também um acerto filosófico, chamarmos a beleza nossa segunda criadora. Pois embora apenas torne possível a humanidade, deixando à nossa vontade livre o quanto queremos realizá-la, a beleza tem em comum com nossa criadora original, a natureza, o fato de que nos concede nada mais senão a capacidade para a humanidade, deixando o uso da mesma depender da determinação de nossa própria vontade. ${ }^{53}$

\begin{abstract}
In the Friedrich Schiller's aesthetics, art undertakes a fundamental political function, since, by his interpretation of the project of modernity, it is the condition of possibility of the authentic political action. The present paper aims to understand how the artist activity represents an overcoming of the aporias Schiller points out in his cultural critique of modernity, especially in what concerns the originary relationship between artistic production, nature and ideal.
\end{abstract}

Keywords: Modernity; aesthetic education; aesthetic freedom.

\title{
Referências bibliográficas.
}

FICHTE, Johann Gottlieb. A Doutrina-da-Ciência de 1794 e outros escritos. 3. ed., trad. Rubens Rodrigues Torres Filho, São Paulo: Nova Cultural, 1988.

HABERMAS, Jürgen. O Discurso Filosófico da Modernidade. Trad. Luiz Sérgio Repa e Rodnei Nascimento, São Paulo: Martins Fontes, 2002.

HENRICH, Dieter. Kunst und Natur in der idealistischen Ästhetik. In: JAUß, Hans Robert. Nachahmung und Illusion. München: Wilhelm Fink Verlag, 1969. (Poetik und Hermeneutik I)

HÖLDERLIN, Friedrich. Sämtliche Gedichte und Hyperion. Frankfurt a.M.: Insel Verlag, 2001. 
HYPPOLITE, Jean. Introdução à Filosofia da História de Hegel. Trad. José Marcos Lima, Rio de Janeiro: Elfos Ed., 1995.

JAUSS, Hans Robert. Der literarische Prozeß des Modernismus von Rousseau bis Adorno. In: HERZOG, Reinhart; KOSELLECK, Reinhart (org.). Epochenschwelle und Epochenbewusstsein. München: Wilhelm Fink Verlag, 1987. - (Poetik und Hermeneutik XII)

KANT, Immanuel. Kritik der reinen Vernunft. Frankfurt a.M.: Suhrkamp, 1974.

Kritik der Urteilskraft. Frankfurt a.M.: Suhrkamp, 1974.

KOSELLECK, Reinhart. Das achtzehnte Jahrhundert als Beginn der Neuzeit. In: HERZOG, Reinhart; KOSELLECK, Reinhart (org.). Epochenschwelle und Epochenbewusstsein. München: Wilhelm Fink Verlag, 1987. - (Poetik und Hermeneutik XII)

PINNA. "Die Natur selbst ist nur eine Idee des Geistes, die nie in die Sinne fällt". Aporie e variazioni del concetto schilleriano di natura. In: PINNA, Giovanna et al. Schiller e il progetto della modernità. Roma: Carocci editore, 2006.

SCHILLER, Friedrich. A educação estética do homem: numa série de cartas. Trad. Roberto Schwarz e Márcio Suzuki, São Paulo: Iluminuras, 2011.

Carta de 13 Julho de 1793 a von Augustenburg. In: Cultura Estética e Liberdade. Trad. Ricardo Barbosa, São Paulo: Hedra, 2009.

Do sublime ao trágico. Trad. Pedro Süssekind e Vladimir Vieira, Belo Horizonte: Autêntica, 2011.

Poesia ingênua e sentimental. Trad. Márcio Suzuki, São Paulo: Iluminuras, 1991.

. Sämtliche Werke: Band I: Gedichte. Dramen I. München: Carl Hanser Verlag, 2004.

. Sämtliche Werke: Band V: Erzählungen. Theoretische Schriften. München: Carl Hanser Verlag, 2004.

SZONDI, Peter. Das Naive ist das Sentimentalische: Zur Begriffsdialektik in Schillers Abhandlung. In: Schriften 2. Franfkurt a.M.: Suhrkamp Verlag, 1978.

\section{Notas}

${ }^{1}$ HÖLDERLIN. Sämtliche Gedichte und Hyperion, p. 240.

["Doch uns gebührt es, unter Gottes Gewittern,

Ihr Dichter! mit entblößtem Haupte zu stehen,

Des Vaters Strahl, ihn selbst, mit eigner Hand

$\mathrm{Zu}$ fassen und dem Volk ins Lied

Gehüllt die himmlische Gabe zu reichen.”] (tradução minha) 
${ }^{2} \mathrm{O}$ descerramento de um futuro aberto (offene Zukunft), como se verá, é um dos elementos presentes na reflexão estética e política de Schiller, sendo portanto um indício de sua pertença a este momento. KOSELLECK. Das achtzehnte Jahrhundert als Beginn der Neuzeit, p. 278.

${ }^{3}$ SCHILLER. Carta de 13 Julho de 1793 a von Augustenburg, p. 73.

${ }^{4}$ Ibid., p. 74-75.

${ }^{5}$ SCHILLER. Sämtliche Werke: Band I: Gedichte. Dramen I, p. 260.

${ }^{6}$ SCHILLER. A educação estética do homem, p. 23 (572). Utilizou-se nas citações as traduções em português, quando existentes, seguindo-se sempre em parêntese a página da edição das obras completas.

${ }^{7}$ Ibid., p. 24 (573).

${ }^{8}$ Dieter Henrich, analisando o caminho de transformação da estética moderna, do fim de uma estética da imitação da natureza (Ästhetik der Naturnachahmung) ao surgimento de uma arte do perspectivismo e da deformação (Kunst des Perspektivismus und der Deformation), procura avaliar a estética idealista a partir de duas de suas teses que, em princípio, seriam contraditórias: i) considerar a arte enquanto único objeto da estética e a obra de arte como diversa da beleza natural segundo seu modo próprio de ser; ii) considerar a arte como um modo próprio de apresentação da verdade, e defender o ideal de arte do classicismo. A ligação com o passado, no ideal clássico, iria contra a ideia de pura produção, que caracteriza a primeira tese.

Nesse contexto, como se verá, Schiller parece se colocar como um ponto-limite na passagem para uma visão da arte enquanto pura produção. $\mathrm{O}$ artista de sua estética, em princípio, é um portador da natureza ou do ideal (também clássico), e sua arte está vinculada à representação disso na obra de arte. Ao mesmo tempo, a origem e o conteúdo da arte encontram-se na essência do próprio sujeito, e não em um locus externo. HENRICH. Kunst und Natur in der idealistischen Ästhetik, p. 128-129.

9 Hans Robert Jauss lê a obra de Rousseau como caminhos possíveis para essa transformação da cultura, que surgem como respostas à seguinte pergunta: como pode o homem no mundo moderno, tendo em vista sua existência cindida como homme civil, reencontrar a totalidade perdida do homme naturel e com isso ganhar novamente a chance de sua felicidade? À diagnose do próprio tempo histórico seguir-se-iam três vias de redenção: para o indivíduo isolado da sociedade, no Emile, por meio do projeto de uma "educação natural"; para o sujeito subsumido na volonté générale, no Contrat social, por meio do projeto de constituição de um Estado de igualdade efetiva; para o pequeno círculo do sentimento, na Nouvelle Héloïse, por meio de uma comunidade amorosa construída ao redor de um casal. Cf. JAUSS. Der literarische Prozeß des Modernismus von Rousseau bis Adorno, p. 251-252. Não se deve deixar de observar que, de certo modo, o projeto de Schiller em A educação estética - uma reforma da natureza humana, por meio de uma educação estética, para a construção de uma comunidade estética - perpassa essas três vias, com diferentes intensidades.

${ }^{10}$ SCHILLER. A educação estética do homem, p. 33 (580).

${ }^{11}$ Ibid., p. 34 (580).

${ }^{12}$ Ibid., p. 31 (579).

13 Observe-se aqui a semelhança com o homem "corrompido" de Rousseau. É interessante observar que, nesse contexto, Schiller já fala na alienação (Entfremdung) do homem.

${ }^{14}$ Ibid., p. 37 (584).

${ }^{15} \mathrm{O}$ termo possui uma história rica entre os contemporâneos de Schiller. Também Hegel aproveita-se dele, em um escrito de juventude, intitulado Positividade da religião cristã. A positividade importa em coação da liberdade, em submissão a leis pré-estabelecidas. Hyppolite esclarece o significado deste termo em Hegel (muito próximo de seu uso em Schiller), quando este fala de uma "religião positiva": "Numa religião positiva há um 
exterioridade para a razão prática. O homem não é livre, submete-se a uma lei que não criou para si mesmo. Assim como para a razão teórica o positivo representa o que se impõe do exterior ao pensamento e que ela tem de receber passivamente, assim também para a razão prática o positivo representa uma ordem e implica entre Deus e o homem uma relação senhor-escravo.” HYPPOLITE. Introdução à Filosofia da História de Hegel, p. 37. Ver também o comentário de Riedel nas obras completas: SCHILLER. Sämtliche Werke: Band V: Erzählungen. Theoretische Schriften, p. 1225.

${ }^{16}$ SCHILLER. A educação estética do homem, p. 43 (588-589).

${ }^{17}$ Ibid., p. 47 (593).

${ }^{18}$ SCHILLER. Carta de 13 Julho de 1793 a von Augustenburg, p. 82.

${ }_{19}$ As três fontes deste ensaio são apontadas por Szondi como "o trabalho poético de Schiller, sua tentativa de diferenciar seu próprio modo poético como não menos legítimo do que o de Goethe, e sua adoção dos princípios kantianos". SZONDI. Das Naive ist das Sentimentalische, p. 70. Importante também é o testemunho de Goethe (p. 67) sobre os embates com Schiller, que se encontrariam à base das motivações de composição do ensaio e, mais tarde, por sua influência em Schlegel, fundariam a diferença entre clássico e romântico.

${ }^{20}$ SCHILLER. Poesia ingênua e sentimental, p. 43 (694).

${ }^{21}$ Ibid., p. 44 (695).

${ }^{22}$ SCHILLER. A educação estética do homem, p. 35 (582).

${ }^{23}$ SCHILLER. Poesia ingênua e sentimental, p. 43 (694). Sobre as variações do conceito de natureza em Schiller, sobre as quais o presente trabalho oferece apenas um esboço assistemático, ver: PINNA. "Die Natur selbst ist nur eine Idee des Geistes, die nie in die Sinne fällt". Aporie e variazioni del concetto schilleriano di natura, p. 71 e ss.

${ }^{24}$ Ibid., p. 48 (700).

${ }^{25}$ Ibid., p. 44 (695-696).

${ }^{26}$ Ibid., p. 61 (718).

${ }^{27}$ Schiller parte de uma proposição kantiana para desenvolver a relação entre o poeta e a natureza: "Gênio é a disposição inata do ânimo, por meio da qual a natureza dá a regra à arte”. KANT, Kritik der Urteilskraft, §46, B182.

${ }^{28}$ SCHILLER. Poesia ingênua e sentimental, p. 51 (704).

${ }^{29}$ A figura inspirada pela natureza, no campo político, é retratada na peça Wilhelm Tell, de Schiller. Seu isolamento da sociedade, mesmo do bando de revoltosos, faz dele um "ser de exceção", portador de forças originárias (ein urkräftigen Heldenmensch, dirá Goethe), próximo da natureza.

${ }^{30}$ SCHILLER. Poesia ingênua e sentimental, p. 57 (712). Nessa passagem, Schiller define pela primeira vez o poeta ingênuo e o sentimental. Esta diferenciação, ainda que de extrema importância, escaparia ao objeto deste trabalho.

${ }^{31}$ Ibid., p. 53 (707).

32 Ibid., p. 72 (733).

${ }^{33}$ Segundo Suzuki, o conceito de "ideal" em Schiller possui um duplo significado: é, por um lado, uma Ideia inalcançável, uma tarefa imposta pela razão e, por outro, um modelo, no sentido de que se atribui, por exemplo, aos artistas gregos para a arte moderna. SCHILLER. A educação estética do homem, p. 138. Cf. KANT, Kritik der reinen Vernunft, A 312 e ss.

${ }^{34}$ SCHILLER. Poesia ingênua e sentimental, p. 61 (717).

${ }^{35}$ Ibid., p. 61 (733).

${ }^{36}$ Ibid., p. 61 (733).

${ }^{37}$ SCHILLER. A educação estética do homem, p. 30 (578).

${ }^{38}$ Ibid., p. 60 (604-605).

${ }^{39}$ Ibid., p. 60 (604-605).

${ }^{40}$ Ibid., p. 63 (606). 
${ }^{41}$ Ibid., p. 76 (618).

${ }^{42}$ Ibid., p. 73 (614).

${ }^{43}$ Ibid., p. 31 (579).

${ }^{44}$ No ensaio Sobre o sublime, Schiller define o homem como o "ser que quer". Uma vez que a vontade é o elemento definidor da humanidade, toda violência - que é a determinação externa da vontade - torna-se uma anulação do humano. Observa-se como o problema da coerção é central em seu pensamento e, em conexão com as Cartas, notase que a coerção pode também ser interna ao homem, como no caso do homem bárbaro e do selvagem. A tarefa da cultura, portanto, na medida em que liberta da coerção, liga-se à realização das potencialidades do homem: "A cultura deve pôr o homem em liberdade e auxiliá-lo a preencher por completo o seu conceito. Portanto, ela deve torná-lo capaz de afirmar sua vontade, pois o homem é o ser que quer". SCHILLER, Do sublime ao trágico, p. 55-56.

${ }^{45}$ SCHILLER. A educação estética do homem, p. 101 (635).

${ }^{46}$ Ibid., p. 102 (635).

47 Ver, por exemplo, a carta a von Augustenburg: "O uso que ela [a geração de revolucionários] fez e faz deste grande presente do acaso demonstra incontestavelmente (...) que aquele, a quem ainda falta muito para a liberdade humana, ainda não está maduro para a liberdade civil." SCHILLER. Carta de 13 Julho de 1793 a von Augustenburg, p. 82.

${ }^{48}$ SCHILLER. A educação estética do homem, p. 108 (640).

${ }^{49}$ Ibid., p. 107 (639).

${ }^{50}$ Utópico aqui em um sentido próximo ao conceito de ideal. Não se trata, pois, de um estágio postergado para um futuro incerto, mas de uma tarefa que se impõe à razão e que, em virtude da separação entre idealidade e realidade, é uma "tarefa infinita" (Unendliche Aufgabe). "Um infinito (...) do qual pode aproximar-se mais e mais no curso do tempo sem jamais alcançá-lo". Ibid., p. 69. A tese de um "futuro aberto" de Koselleck - ou seja, a abertura para um futuro, no qual algo novo se estabelecerá e cuja aproximação permanece como uma tarefa - encontra correspondência com este conceito, que Schiller toma de Fichte e Kant. Ver FICHTE. A Doutrina-da-Ciência de 1794, p. 58. KANT, Kritik der reinen Vernunft, A 315.

${ }^{51}$ Ibid., p. 134. Os reflexos dessa visão libertadora da arte podem ser visto na teoria dos gêneros de Poesia ingênua e sentimental. O idílio corresponde à apresentação poética do ideal de humanidade, que inspira o homem inserido na cultura: "Que se imponha como tarefa um idílio que realize a inocência bucólica mesmo nos indivíduos de cultura (...); numa palavra, um idílio que conduza ao Elísio o homem que já não pode retornar à Arcádia". SCHILLER. Poesia ingênua e sentimental, p. 87 (750).

${ }^{52}$ HABERMAS. O discurso filosófico da modernidade, p. 66.

${ }^{53}$ SCHILLER. A educação estética do homem, p. 102-103 (636). 